\title{
Tax Competition, Relative Performance and Policy Imitation
}

\author{
ANDREAS WAGENER \\ CESIFO WORKING PAPER No. 2723 \\ CATEGORY 1: PUBlic FINANCE \\ JULY 2009
An electronic version of the paper may be downloaded
- from the SSRN website: Www.SSRN.com
- from the RePEc website: $\quad$ www.RePEc.org \\ - from the CESifo website: www.CESifo-group.org/wp
}




\title{
Tax Competition, Relative Performance and Policy Imitation
}

\begin{abstract}
Rather than about absolute payoffs, governments in fiscal competition often seem to care about their performance relative to other governments. Moreover, they often appear to mimic policies observed elsewhere. We study such behaviour in a tax competition game with mobile capital à la Zodrow-Mieszkowski. Both with relative payoff concerns and for imitative policies, evolutionary stability is the appropriate solution concept. It renders tax competition more aggressive than with best-reply policies (Nash equilibrium). Whatever the number of jurisdictions involved, an evolutionary stable tax policy coincides with the competitive outcome of a tax competition game played among infinitely many governments. Tax competition among boundedly rational governments, thus, involves drastic efficiency losses.
\end{abstract}

JEL Code: H77, H75, C73.

Keywords: fiscal competition, relative performance, tax mimicking, evolutionary stability.

\author{
Andreas Wagener \\ University of Hannover \\ Department of Economics and Management \\ Koenigsworther Platz 1 \\ 30167 Hannover \\ Germany \\ wagener@sopo.uni-hannover.de
}




\section{Introduction}

Models of fiscal competition routinely analyse Nash equilibria of intergovernmental games. Underlying the idea of a Nash-equilibrium is the hypothesis of best-reply behaviour: Governments set their policies in response to those of other governments with the aim of maximizing their own payoffs (whatever this may be: social welfare, the utility of a Leviathan decision-maker, re-election probabilities of politicians, tax revenues etc.)

In this paper, we depart from the hypotheses of best-response play and payoff maximization and analyse tax competition from a behavioural perspective. We, first, consider governments that care about relative payoffs, i.e., governments that aim at maximizing the distance between their own payoff and that in other jurisdictions (on the same hierarchical level in a federal system). Second - but, as will turn out, with an identical prediction for long-run outcomes - we analyse dynamic fiscal interactions where (boundedly rational) governments mimic tax strategies of other governments that have performed well in the previous period of the game.

Adding to the literature on fiscal competition concerns about relative performance and/or imitative behaviour is motivated by a number of suggestive theoretical and empirical observations:

- The theory of yardstick competition - which underlies the hypothesis that fiscal decentralization dominates centralization on informational grounds - posits that in a multi-jurisdictional setting politicians face a "rank tournament" (Salmon, 1987; Besley and Case, 1995): Voters can observe policy outcomes in other jurisdictions and compare them to domestic policies. Hence, politicians expect that a good [poor] relative performance will increase [diminish] their popularity. If voters consider relative performance important, rational politicians will share that view.

- Empirical evidence indicates that rather than optimizing their policies, (local) governments often simply adopt successful policies observed elsewhere. This encompasses both tax policies and expenditure patterns. ${ }^{1}$ While there exist several potential motives for unison policies (tax competition, reference points, lack of inventive

\footnotetext{
${ }^{1}$ In the context of taxation, mimicking has been observed with local jurisdictions, e.g., in the U.S. (Ladd, 1992), Belgium (Heyndels and Vuchelen, 1998), The Netherlands (Allers and Elhorst, 2005), Spain (Solé-Ollé, 2003), Italy (Bordignon et al. 2003), Germany (Büttner, 2001) or Switzerland (Feld and Reulier, 2009). It also seems to prevail in international tax competition (Altshuler and Goodspeed, 2006). Revelli (2006) finds evidence for mimicking expenditure patterns in the social service provision of UK local authorities; Kelejian and Robinson (1993) for police expenditure in US counties; Heyndels and
} 
talent, saving costs of decision making etc.), the most likely source of tax and expenditure mimicking seems to be concerns about the relative standing vis-à-vis other governments (see Case, 1993; Allers and Elhorst, 2005; Bordignon et al., 2003; Solé-Ollé, 2003; for an exception see Geys, 2006).

- Since the Lisbon summit, the European Union has endorsed the so-called Open Method of Coordination (OMC) as one of its modes of governance. The OMC is an iterative procedure of mimicking and experimenting (Zeitlin, 2007). It promotes that national governments adopt what turned out to be best-practise policies. The effectiveness of the OMC hinges on the assumption that governments - for fear of peer pressure, naming and shaming, or bad press - care about relative rather than about absolute performance.

- Inspired by Hayekian ideas, fiscal competition is often regarded as advantageous over centralization as a discovery procedure and selection mechanism for policy innovations. Like in a laboratory, autonomous local governments can experiment with new policies without causing big damage to the economy as a whole (Oates, 1999, section 5). In an evolutionary process of imitation and learning, best practices will then spread across jurisdictions, improving efficiency over time. While such ideas are widely quoted and even thought to underlie shifts in real-world federal systems, ${ }^{2}$ hardly any theoretical research exists on the validity of such evolutionary hypotheses. ${ }^{3}$

In this paper, we analyse competition between governments that, in an economically integrated area with fiscal externalities, care about their relative performance or, in a dynamic version, imitate (with some experimentation) well-performing policies of other governments. We do so in the most widely used framework in fiscal federalism, the Zodrow-Mieszkowski (1986) or Wilson (1986) tax competition model, where a governmentprovided consumption good or input factor has to be financed out of a source tax on mobile capital. For absolute payoff maximization, this model predicts inefficient allocations: If Vuchelen (1998) for local public expenditures in Belgium; Fredriksson et al. (2004) for multiple policy instruments in the US.

${ }^{2}$ See, e.g., Oates (1999) or Inman and Rubinfeld (1997) on welfare reforms in the U.S., or Borrás and Jacobsson (2004) on the Open Method of Coordination in the EU.

${ }^{3}$ Some contributions deal, however, with the efficiency of policy search under various degrees of fiscal decentralization (Kollman et al., 2000) or with the incentives to innovate in federations (Kotsogiannis and Schwager, 2008). 
the government provides a consumption good, the Nash equilibrium in tax competition entails underprovision and too low taxes while the tax-financed provision of an input factor may lead to under- or overprovision, depending on properties of the production technology (Noiset, 1995; Dhillon et al., 2007). Inefficiencies (in whatever direction) are more pronounced the more jurisdictions are involved in the fiscal game (Hoyt, 1991). The worst case is the "competitive" one with a large (technically: infinite) number of small jurisdictions.

Turning to relative rather than absolute payoff maximization, evolutionary stable strategies (ESS) are the appropriate solution concept (Schaffer, 1988). Interestingly, analysing the game in a dynamic version where local governments adopt, with some experimentation, best practices yields the same outcome: the set of possible long-run outcomes (precisely, the set of stochastically stable states) of imitation dynamics with experimentation (only) contains ESS. Hence, in a meaningful way, relative payoff-maximization and mimicking behaviour can be viewed as equivalent: they both lead to ESS.

Even more interestingly, whatever the number of participating jurisdictions, the ESS in a tax competition game is always the same and it coincides with the competitive Nash equilibrium (i.e., the Nash equilibrium in the tax competition game played among infinitely many jurisdictions). This, however, implies that relative performance concerns (or, for that reason, imitative behaviour) in tax competition lead to worse performance than absolute payoff-maximization. This result holds regardless of the direction into which the inefficiency goes; relative payoff concerns accelerate a race-to-the-bottom as well as a race-over-the-top.

A rough intuition for this is as follows: ${ }^{4}$ With relative payoff concerns, there are (in principle) two ways to improve one's position: increasing one's own payoff or making that of others deteriorate (spiteful behaviour; Hamilton, 1970). For absolute payoff maximization only the first channel is relevant. In tax competition games with mobile capital harm can be imposed on other governments if one lures capital out of their jurisdiction by, say, lowering one's tax rate or offering more public inputs. The incentive for undercutting or overbidding is already present in standard tax competition but is further incited when relative concerns enter. Hence, policy instruments are used in a more aggressive way and inefficiencies are worsened.

This observation casts a shadow on the Hayekian view on tax competition. Laboratory federalism with experimentation and imitation of best practise appears less benign than

\footnotetext{
${ }^{4}$ More detailed intuition will be provided in Section 2.4.
} 
the narrative of the "discovery procedure" wishes to imply. Imitation (even of wellperforming policies) is a boundedly rational form of behaviour. With externalities among actors there is no guarantee that it will lead to an efficient outcome in the aggregate (see Alòs-Ferrer and Schlag, 2009). Tax competition and fiscal federalism seem to be a case in point.

In summary, behavioural tax competition - when governments care for relative performance or, likewise, mimic best practises - makes fiscal interaction more competitive, even if there are only very few jurisdictions involved. This result (although not the mechanics behind it) is akin to findings from oligopoly theory: In a Cournot oligopoly, relative payoff maximization leads to competitive outcomes (rather than to the Cournot-Nash equilibrium): prices are set to equate marginal costs (Vega-Redondo, 1997).

Let us emphasize the novel ingredients in our analysis, compared to existing literature on tax competition. Our approach differs from yardstick competition in that it does, first, not build on information issues and, second, includes fiscal externalities - which are absent from the standard models of yardstick competition. ${ }^{5}$ Our approach is distinguished from standard tax competition games by assuming relative payoff maximization. And our approach allows for a dynamic, Hayekian interpretation of tax competition as a diffusion mechanism for best practices (although with some unwarranted results).

The rest of this paper is structured as follows: Section 2 analyses fiscal interaction in a scenario where taxes on mobile capital go to finance a government-provided consumption good. Nash equilibria (absolute payoff maximization) and ESS (relative performance concerns and/or imitative behaviour) are derived and compared. Section 3 does the same for a fiscal game with public input provision where tax competition may lead to overprovision/overtaxation. Section 4 briefly concludes.

\section{Tax competition with public consumption goods}

\subsection{The model}

The framework for our analysis of tax competition stems from the seminal contributions by Zodrow and Mieszkowski (1986, Section 2), Wilson (1986), or Hoyt (1991). We consider an economically integrated area with a finite, but not necessarily large number $n>1$

\footnotetext{
${ }^{5}$ This is highlighted by Bordignon et al. (2004). Externalities in yardstick competition are information spill-overs.
} 
of identical jurisdictions. ${ }^{6}$ Each jurisdiction $i \in\{1, \ldots, n\}$ is inhabited by one (representative) immobile household who owns an (unmodelled) fixed factor and some initial stock of capital $\bar{k}>0$. Capital is costlessly mobile and can be invested at home or in any other jurisdiction.

Each jurisdiction produces a single output $y_{i}$ (which also serves as the numéraire), employing an amount $k_{i}$ of capital invested and the fixed factor. The production technology is represented by a production function $y_{i}=f\left(k_{i}\right)$, with $f^{\prime}(k)>0>f^{\prime \prime}(k)$ for all $k>0$. To avoid uninteresting corner solutions, we assume that $f$ satisfies Inada-type conditions (i.e., $f^{\prime}(0) \rightarrow \infty$ and $\left.f^{\prime}(\infty) \rightarrow 0\right)$.

Local output $y_{i}$ can be costlessly transformed into consumption, $c_{i}$, or a governmentprovided good or service, $g_{i}$ (hence, the marginal rate of transformation between the private and the publicly provided good is one). Expenditures for the publicly provided good or service have to be financed with a proportional tax on the amount of capital invested in the jurisdiction. Governments maintain balanced budgets. Denoting the capital tax rate in jurisdiction $i$ by $t_{i}$ we, thus, require

$$
t_{i} \cdot k_{i}=g_{i} \text { for all } i=1, \ldots, n \text {. }
$$

Given the perfect mobility of capital within the economic area, in a capital market equilibrium the net-of-tax return on capital will be equalized across jurisdictions. With capital taxes $\mathbf{t}=\left(t_{1}, \ldots, t_{n}\right)$, a capital market equilibrium is a distribution of capital $\left(k_{1}(\mathbf{t}), \ldots, k_{n}(\mathbf{t})\right)$ and a level of $\rho(\mathbf{t})$ such that:

$$
\begin{aligned}
f^{\prime}\left(k_{i}(\mathbf{t})\right)-t_{i} & =\rho(\mathbf{t}) \quad \text { for } i=1, \ldots, n ; \\
\sum_{i=1}^{n} k_{i}(\mathbf{t}) & =n \cdot \bar{k} .
\end{aligned}
$$

The representative individual in $i$ cares for private consumption and the publicly provided good; his preferences are reflected by a utility function

$$
u^{i}=U\left(c_{i}, g_{i}\right)
$$

$(i=1, \ldots, n)$, where $U$ is monotonically increasing in both arguments and strictly quasiconcave. Partial derivatives of $U$ are denoted through subscripts (e.g., $U_{g}$ or $U_{c g}$ ). We

\footnotetext{
${ }^{6}$ Zodrow and Mieszkowski (1986) and Wilson (1986) model a purely competitive setup (jurisdictions perceive themselves to have no impact on the economy-wide rate of return on capital). Our specification encompasses that case when $n$ is very large. Also see Section 2.4.
} 
assume that both $c$ and $g$ are normal goods. ${ }^{7}$ Private consumption emerges as output plus the return on net capital exports minus local taxes:

$$
c_{i}=f\left(k_{i}\right)-t_{i} k_{i}+\rho\left(\bar{k}-k_{i}\right)
$$

The straightforward comparative statics of the $k_{i}(\mathbf{t})$ and of $\rho(\mathbf{t})$ can be obtained from (1) and (2) via the Implicit Function Theorem. We first confirm that higher taxes levied in jurisdiction $i$ lead to an outflow of capital from there:

$$
\frac{\partial k_{i}(\mathbf{t})}{\partial t_{i}}=\frac{1}{f^{\prime \prime}\left(k_{i}\right)} \cdot\left(1-\frac{1 / f^{\prime \prime}\left(k_{i}\right)}{\sum_{h=1}^{n} 1 / f^{\prime \prime}\left(k_{h}\right)}\right)<0
$$

We henceforth capture the domestic effects of tax changes by the elasticity of capital invested in country $i$ with respect to the tax rate there:

$$
\eta_{i}(\mathbf{t}):=\frac{\partial k_{i}(\mathbf{t})}{\partial t_{i}} \cdot \frac{t_{i}}{k_{i}(\mathbf{t})}<0
$$

Higher taxes in one jurisdiction lead to increases in the amount of capital invested elsewhere:

$$
\frac{\partial k_{j}(\mathbf{t})}{\partial t_{i}}=-\frac{1}{f^{\prime \prime}\left(k_{i}\right) f^{\prime \prime}\left(k_{j}\right) \sum_{h=1}^{n} 1 / f^{\prime \prime}\left(k_{h}\right)}>0
$$

for all $j \neq i$. An increase in any tax rate lowers the equilibrium rate of return:

$$
\frac{\partial \rho(\mathbf{t})}{\partial t_{i}}=-\frac{1}{f^{\prime \prime}\left(k_{i}\right) \sum_{h=1}^{n} 1 / f^{\prime \prime}\left(k_{h}\right)}<0
$$

for all $i$. Ob* serve that with a symmetric tax vector $\left(t_{i}=t\right.$ for all $\left.i\right)$ all jurisdictions employ the same amount of capital, which is equal to their initial endowment: $k_{i}=\bar{k}$. Moreover, at a symmetric tax vector,

$$
\begin{aligned}
\frac{\partial k_{i}}{\partial t_{i}} & =\frac{1}{f^{\prime \prime}(\bar{k})} \cdot\left(1-\frac{1}{n}\right)<0 ; \\
\frac{\partial k_{j}}{\partial t_{i}} & =-\frac{1}{n f^{\prime \prime}(\bar{k})}>0 \\
\frac{\partial \rho}{\partial t_{i}} & =-\frac{1}{n}<0
\end{aligned}
$$

for all $i \neq j$. Let us introduce some special notation for symmetric situations. When all jurisdictions set the same tax rate (i.e., $\mathbf{t}=(t, \ldots, t)$ for some $t \in T$ ), then $k_{i}(\mathbf{t})=\bar{k}$ for all $i$. Attending are levels of private and of public consumption that are identical

\footnotetext{
${ }^{7}$ Formally, $U_{g g} U_{c}-U_{c g} U_{g}<0$ and $U_{c c} U_{g}-U_{c g} U_{c}<0$. This assumption ensures that $\partial\left(U_{g} / U_{c}\right) / \partial g<0$.
} 
across jurisdictions, but that vary with the common tax rate $t$. We shall denote these consumption levels by $\bar{c}(t)$ and $\bar{g}(t)$. Observe that $\bar{g}(\mathbf{t})=f(\bar{k})-\bar{c}(t)$. Similarly, we write as $\bar{\eta}(t ; n)$ the value of $\eta_{i}(\mathbf{t})$ at a symmetric tax vector with rate $t$ in a setting of $n$ jurisdictions. From (3), $\bar{\eta}$ can be calculated as

$$
\bar{\eta}(t ; n)=\frac{t}{\bar{k} f^{\prime \prime}(\bar{k})}\left(1-\frac{1}{n}\right) .
$$

When setting their capital taxes, governments care for the utility of their representative citizens and take into account that capital relocates upon tax changes.

\subsection{Payoffs and solution concepts}

Given taxes $\mathbf{t}$ and an attending capital market equilibrium, jurisdiction $i$ 's (absolute) payoff can be expressed as

$$
\pi\left(t_{i} ; \mathbf{t}_{-i}\right)=U\left(f\left(k_{i}(\mathbf{t})\right)-t_{i} k_{i}(\mathbf{t})+\rho(\mathbf{t})\left(\bar{k}-k_{i}(\mathbf{t})\right), t_{i} k_{i}(\mathbf{t})\right)
$$

Here $\mathbf{t}_{-i}$ contains all tax rates other than that of country $i$. The payoff function (6) is symmetric: payoffs do not depend on a jurisdiction's index and are invariant to permutations of the other jurisdictions' strategies. Each jurisdiction chooses a tax rate from a common strategy set, given by a compact set of tax rates $T=[0, \bar{t}]$ where $\bar{t}<\infty{ }^{8}$

As the game is symmetric, we focus on symmetric equilibria. Let us recall the definitions of symmetric Nash equilibrium and finite-population evolutionarily stable strategy (ESS) and shortly comment on the difference between the two concepts.

Definition 1 - A strategy $t^{N} \in T$ is played in a symmetric Nash equilibrium if

$$
\pi\left(t^{N} ; t^{N}, \ldots, t^{N}\right) \geq \pi\left(t ; t^{N}, \ldots, t^{N}\right) \quad \text { for all } t \in T
$$

- A strategy $t^{E} \in T$ is said to be an evolutionarily stable strategy (ESS) if

$$
\pi\left(t^{E} ; t, t^{E}, \ldots, t^{E}\right) \geq \pi\left(t ; t^{E}, \ldots, t^{E}\right) \quad \text { for all } t \in T \text {. }
$$

In a Nash equilibrium no jurisdiction would strictly benefit from a deviation, given the tax rates of the other jurisdictions. In an evolutionarily stable profile no jurisdiction would be able to gain a strict relative advantage by deviating. While in a Nash equilibrium

\footnotetext{
${ }^{8}$ Presupposing some - potentially very high - upper bound on tax rates is innocuous; it just keeps strategy sets compact.
} 
one compares the deviator's payoffs before and after deviation, in an evolutionarily stable profile one compares the payoffs to a (single) deviator, choosing tax rate $t$, with the payoffs to the non-deviators, choosing $t^{E}$ (Schaffer, 1988). If the number of jurisdictions is finite and each jurisdiction has non-negligible impact on the payoffs of all others, it may pay in relative terms to deviate from a Nash equilibrium, if the loss imposed on non-deviators exceeds the loss suffered by the deviator itself. Conversely, there may be incentives, in terms of absolute payoffs, to deviate from an ESS. However, by definition, any deviatior would be worse off in relative terms after such deviation. This holds even if the deviating government cleverly chooses its deviation as a best reply to the other governments' tax rates.

A Nash equilibrium will emerge when governments strive for absolute payoff maximization. The ESS, however, is the appropriate solution concept where governments care about their comparative performance. As observed by Schaffer (1988), an ESS corresponds to a symmetric Nash equilibrium of the game with relative payoffs. Formally, an ESS is a strategy $t^{E}$ such that

$$
t^{E}=\arg \max _{t \in T}\left[\pi\left(t ; t^{E}, \ldots, t^{E}\right)-\pi\left(t^{E} ; t, t^{E}, \ldots, t^{E}\right)\right] .
$$

As (7) indicates, a finite-population ESS does not generally correspond to a Nash equilibrium strategy of the original game (see Guse et al., 2008). As we shall see soon, Nash equilibrium and ESS do indeed differ significantly in a tax competition game.

\subsection{Nash equilibrium}

The (symmetric) Nash equilibrium of the Zodrow-Mieszkowski model is well understood. Jurisdiction $i$ 's best response is implicitly given by

$$
\begin{aligned}
\frac{\partial \pi\left(t_{i} ; \mathbf{t}_{-i}\right)}{\partial t_{i}} & =U_{c}\left(\left(f^{\prime}\left(k_{i}\right)-t_{i}-\rho\right) \cdot \frac{\partial k_{i}}{\partial t_{i}}-k_{i}+\frac{\partial \rho}{\partial t_{i}} \cdot\left(\bar{k}-k_{i}\right)\right)+U_{g}\left(t_{i} \cdot \frac{\partial k_{i}}{\partial t_{i}}+k_{i}\right) \\
& =-U_{c}\left(k_{i}-\frac{\partial \rho}{\partial t_{i}} \cdot\left(\bar{k}-k_{i}\right)\right)+U_{g}\left(t_{i} \cdot \frac{\partial k_{i}}{\partial t_{i}}+k_{i}\right)=0 .
\end{aligned}
$$

With symmetry $\left(t_{i}=t^{N}\right.$ and, consequently, $k_{i}=\bar{k}$ for all $\left.i\right)$, rearranging terms leads to the following equilibrium condition:

$$
\frac{U_{g}\left(\bar{c}\left(t^{N}\right), \bar{g}\left(t^{N}\right)\right)}{U_{c}\left(\bar{c}\left(t^{N}\right), \bar{g}\left(t^{N}\right)\right)}=\frac{1}{1+\bar{\eta}\left(t^{N} ; n\right)} .
$$

Observe that, for all $t>0$,

$$
n^{\prime}>n \quad \Longrightarrow \quad \bar{\eta}\left(t ; n^{\prime}\right)>\bar{\eta}(t ; n) .
$$


Hence, together with the normality of $c$ and $g$ we obtain the following well-known proposition: ${ }^{9}$

Result 1 (i) (Zodrow and Mieszkowski, 1986) Tax competition leads to an underprovision of publicly provided goods.

(ii) (Hoyt, 1991) This underprovision is more pronounced the higher $n$, i.e., the more jurisdictions are involved in the tax competition game.

The case $n \rightarrow \infty$ is often referred to as the small-jurisdiction or competitive scenario; this is the case originally envisaged in Zodrow and Mieszkowski (1986). From Result 1(ii), it is the scenario where tax competition is sharpest and the underprovision problem most severe.

\subsection{ESS}

Recalling (7), we define the payoff difference between a mutant and a non-mutant country as

$$
\psi\left(t, t^{\prime}\right):=\pi\left(\mathbf{t}^{1}\left[t, t^{\prime}\right]\right)-\pi\left(\mathbf{t}^{2}\left[t, t^{\prime}\right]\right)
$$

where, given $t, t^{\prime} \in T$, we use $\mathbf{t}^{1}\left[t, t^{\prime}\right]$ and $\mathbf{t}^{2}\left[t, t^{\prime}\right]$ as shortcut notation for the tax vectors

$$
\mathbf{t}^{1}\left[t, t^{\prime}\right]=\left(t ; t^{\prime}, \ldots, t^{\prime}\right) \quad \text { and } \quad \mathbf{t}^{2}\left[t, t^{\prime}\right]=\left(t^{\prime} ; t, t^{\prime}, \ldots, t^{\prime}\right)
$$

For $t^{\prime} \in T$, consider the following maximization problem:

$$
\max _{t \in T} \psi\left(t, t^{\prime}\right) .
$$

Following Tanaka (2000), a strategy $t^{E}$ is an ESS if and only if it solves the above problem for $t^{\prime}=t^{E}$, i.e., iff

$$
t^{E}=\arg \max _{t \in T} \psi\left(t, t^{E}\right) .
$$

${ }^{9}$ An efficient provision level $g^{*}$ satisfies

$$
\frac{U_{g}\left(f(\bar{k})-g^{*}, g^{*}\right)}{U_{c}\left(f(\bar{k})-g^{*}, g^{*}\right)}=1 .
$$

For a Nash equilibrium we get from (8) that

$$
\frac{U_{g}\left(f(\bar{k})-g\left(t^{N}\right), g\left(t^{N}\right)\right)}{U_{c}\left(f(\bar{k})-g\left(t^{N}\right), g\left(t^{N}\right)\right)}>1 .
$$

Normality of $c$ and $g$ then implies that $g\left(t^{N}\right)<g^{*}$. The monotonicity of $g\left(t^{N}\right)$ in $n$ follows by a similar token. 
If (9) holds, $\psi$ takes its maximum value, which is zero. Without loss in generality, we use in the following labels " 1 " and "2" to indicate, respectively, the mutant and a non-mutant jurisdiction. We view relative payoffs from the perspective of jurisdiction 1. For our game we then get

$$
\begin{aligned}
\psi\left(t, t^{\prime}\right)=U & \left(f\left(k_{1}\left(\mathbf{t}^{1}\right)\right)-t k_{1}\left(\mathbf{t}^{1}\right)+\rho\left(\mathbf{t}^{1}\right)\left(\bar{k}-k_{1}\left(\mathbf{t}^{1}\right)\right), t k_{1}\left(\mathbf{t}^{1}\right)\right) \\
& -U\left(f\left(k_{2}\left(\mathbf{t}^{2}\right)\right)-t^{\prime} k_{2}\left(\mathbf{t}^{2}\right)+\rho\left(\mathbf{t}^{2}\right)\left(\bar{k}-k_{2}\left(\mathbf{t}^{2}\right)\right), t^{\prime} k_{2}\left(\mathbf{t}^{2}\right)\right)
\end{aligned}
$$

(observe that $\rho\left(\mathbf{t}^{1}\right)=\rho\left(\mathbf{t}^{2}\right)$ ). To find the maximum of (10) with respect to $t$, we partially differentiate: ${ }^{10}$

$$
\begin{aligned}
\frac{\partial \psi\left(t, t^{\prime}\right)}{\partial t}= & -U_{c}^{1}\left(k_{1}-\frac{\partial \rho\left(\mathbf{t}^{1}\right)}{\partial t} \cdot\left(\bar{k}-k_{1}\right)\right)+U_{g}^{1}\left(t \cdot \frac{\partial k_{1}}{\partial t}+k_{1}\right) \\
& +U_{c}^{2}(\underbrace{\left(f^{\prime}\left(k_{2}\right)-t^{\prime}-\rho\right)}_{=0} \cdot \frac{\partial k_{2}}{\partial t}+\frac{\partial \rho\left(\mathbf{t}^{1}\right)}{\partial t_{2}} \cdot\left(\bar{k}-k_{2}\right))-U_{g}^{2}\left(t^{\prime} \cdot \frac{\partial k_{2}}{\partial t}\right)
\end{aligned}
$$

At a symmetric profile $\left(t=t^{\prime}\right)$, we have $\mathbf{t}^{1}\left[t^{\prime}, t^{\prime}\right]=\mathbf{t}^{2}\left[t^{\prime}, t^{\prime}\right]$ and $k_{1}=k_{2}=\bar{k}$. Moreover, $c_{1}=c_{2}=\bar{c}\left(t^{\prime}\right)$ and $g_{1}=g_{2}=\bar{g}\left(t^{\prime}\right)$. Consequently, $U_{c}^{1}=U_{c}^{2}$ and $U_{g}^{1}=U_{g}^{2}$. Hence,

$$
\begin{aligned}
\frac{\partial \psi\left(t^{\prime}, t^{\prime}\right)}{\partial t} & =-\bar{k} U_{c}^{1}+U_{g}^{1}\left(\bar{k}+t^{\prime} \cdot\left[\frac{\partial k_{1}}{\partial t_{1}}-\frac{\partial k_{2}}{\partial t_{1}}\right]\right) \\
& =-\bar{k} U_{c}\left(\bar{c}\left(t^{\prime}\right), \bar{g}\left(t^{\prime}\right)\right)+U_{g}\left(\bar{c}\left(t^{\prime}\right), \bar{g}\left(t^{\prime}\right)\right) \cdot\left(\bar{k}+\frac{t^{\prime}}{f^{\prime \prime}(\bar{k})}\right) .
\end{aligned}
$$

As a maximizer of $\psi$, an ESS $t^{E}$ solves $\partial \psi / \partial t=0$ or, equivalently, satisfies the following condition:

$$
\begin{aligned}
\frac{U_{g}\left(\bar{c}\left(t^{E}\right), \bar{g}\left(t^{E}\right)\right)}{U_{c}\left(\bar{c}\left(t^{E}\right), \bar{g}\left(t^{E}\right)\right)} & =\frac{\bar{k}}{\bar{k}+t^{E} / f^{\prime \prime}(\bar{k})} \\
& =\frac{1}{1+\bar{\eta}\left(t^{E}, \infty\right)} .
\end{aligned}
$$

Hence,

Result 2 An ESS of a tax competition game is, for any number of jurisdictions, identical to the Nash equilibrium in a competitive tax competition.

An ESS in tax competition has the following properties: It is independent of the number of jurisdictions, and it always ${ }^{11}$ coincides with the "competitive" Nash equilibrium.

\footnotetext{
${ }^{10}$ With a slight abuse in notation we denote by $\partial k_{1} / \partial t:=\partial k_{1}\left(t ; t^{\prime}, \ldots, t^{\prime}\right) / \partial t_{1}$, i.e., the derivative of $k_{1}\left(\mathbf{t}^{1}\right)$ with respect to the first argument (i.e., with respect to jurisdiction 1's own tax rate). By $\partial k_{2} / \partial t$ we correspondingly mean the partial derivative $\partial k_{2}\left(t^{\prime} ; t, t^{\prime}, \ldots, t^{\prime}\right) / \partial t_{1}$ - i.e., again the derivative with respect to jurisdiction 1's tax rate. Likewise we proceed with derivatives of $\rho$.

${ }^{11}$ In case of $n \rightarrow \infty$, the identity of a (unique) Nash equilibrium and ESS is a standard result; it follows from the fact the ESS refines Nash equilibria.
} 
Governments with concerns about relative performance exacerbate the underprovision problem, as compared to "normal" tax competition. As a consequence, also social welfare $u$ is strictly lower.

Let us first provide an intuition why tax competition is sharper when based on relative performance. Assume a symmetric situation such that capital is distributed uniformly over the economic area and all governments obtain the same payoff level. When contemplating a tax change, a government that only cares about its own payoff would assess whether the effects on local private consumption outweigh the effects on government-provided good (which works through the government budget); this is the essence of (8) or of the first line in (11). A government that cares about its relative standing vis-à-vis other governments additionally takes into account the effects on private consumption and the government budget elsewhere. In a symmetric situation a (small) tax change in $i$ does not affect private consumption in $j$. However, a tax cut in $i$ leads (via the outflow of capital from $j$ ) to lower tax revenues in $j$ and, thus, to a reduction in the provision of the government good. The resulting deterioration of social welfare in $j$ is, however, to the relative advantage of $i{ }^{12}$ Concerns about relative performance involve an additional benefit from tax reductions. Being able to worsen the budgetary situation elsewhere by cutting taxes at home sharpens the incentives for lowering taxes. As a consequence, the underprovision of government-provided goods exacerbates.

To understand why the ESS of the tax competition game is (unlike the Nash equilibrium) independent of the number of participating jurisdictions, verify from (12) that changes in relative payoffs are, starting from a symmetric situation, driven by differentials in capital investments, i.e., by the change of $\left(k_{i}-k_{j}\right)$. From (3) and (4) it is formally clear that $\partial\left(k_{i}-k_{j}\right) / \partial t_{i}$ is independent of $n$. An economic argument comes from the no-arbitrage conditions (1). Partially differentiating with respect to the tax rate $t_{i}$ yields:

$$
\frac{\partial k_{i}}{\partial t_{i}}=\frac{1}{f^{\prime \prime}\left(k_{i}\right)} \cdot\left[1+\frac{\partial \rho}{\partial t_{i}}\right] \text { and } \quad \frac{\partial k_{j}}{\partial t_{i}}=\frac{1}{f^{\prime \prime}\left(k_{j}\right)} \cdot \frac{\partial \rho}{\partial t_{i}} .
$$

Hence, the effect of a jurisdiction's tax rate on its own capital can be decomposed into a direct tax effect (captured by "1" in the square brackets) and a rate-of-return effect $\partial \rho / \partial t_{i}$. The cross-border impact of changes in $t_{i}$ on $k_{j}$ is only driven by this rate-ofreturn effect - which is common to all jurisdictions and which is weaker when there are more jurisdictions over which it can be spread (see (5)). For the relative positions of jurisdictions, this common rate-of-return effect is irrelevant in symmetric situations; it

\footnotetext{
${ }^{12}$ This is sometimes referred to as spiteful behaviour in evolutionary game theory (Hamilton, 1970).
} 
cancels out in $\partial\left(k_{i}-k_{j}\right) / \partial t_{i}$. Only the direct tax effect survives, which, however, is independent of the number of jurisdictions. Consequently, the ESS is independent of $n$, too.

The cancelling-out of the common rate-of-return with relative payoff comparisons also helps to explain why the ESS coincides with the competitive Nash equilibrium. The latter emerges if jurisdictions do not (perceive to) have an impact on the equilibrium rate of return (for $n \rightarrow \infty$, none of the jurisdictions has market power: $\partial \rho / \partial t_{i}=0$ ). Though the cause is different, ${ }^{13}$ this irrelevance of changes in $\rho$ has the same effect as in an ESS.

The result that the ESS in tax competition corresponds to the competitive case of "normal" tax competition is in line with observations in the oligopoly literature. E.g., the ESS in Cournot games coincides with the Walrasian (= price-taking, competitive) outcome (see Vega-Redondo, 1997; Alòs-Ferrer and Ania, 2005).

\subsection{Mimicking and ESS}

So far, the use of ESS as a solution concept in tax competition has been motivated by the presumption that governments care about relative performance. As discussed in the introduction, substantial empirical evidence suggests that governments mimic the behaviour of other governments. One might conjecture that such mimicking is behaviourally related to concerns for relative performance. Relying on ideas developed by Kandori and Rob (1995), Kandori et al. (1993), and Vega-Redondo (1997), we make this connection precise here.

Suppose the tax competition game is played in each period over a long time horizon, say in periods $\tau=0,1,2, \ldots$. Instead of assuming that $t$ can be continuously chosen from an interval $[0, \bar{t}]$, we shall assume that there is a (suitably fine) grid $G=\{0, \delta, 2 \delta, \ldots, \nu \delta\}$ with $\delta>0$ and $\nu \in \mathbb{N}$, but arbitrary, from which tax rates can be chosen. ${ }^{14}$ We assume that $t^{E}$ is on the grid. Any tax rate adopted by a jurisdiction has to come from the grid $G$.

Consider the following imitation dynamics with experimentation:

- Imitation: In each period $\tau \geq 1$ each government mimics one of the tax rates that

\footnotetext{
${ }^{13}$ Formally, this can be seen from the second-order conditions of the attending maximization problems. See Tanaka (2000) for a discussion in an oligopoly context.

${ }^{14}$ This assumption is made for tractability. Moreover, it matches reality - where the grid density is measured in (tenths of) percentage points - even better than the continuum assumption. For discussion of a continuum of strategies see, e.g., Schenk-Hoppé (2000).
} 
performed best (in terms of absolute payoffs) in the previous period. A government that was among the best performers in the previous period will not change its strategy. If all governments chose the same tax rate in the previous period, then no adjustment will occur.

- Experimentation: With independent probability $\varepsilon>0$, each government ignores the rule to imitate and chooses a tax rate in $G$ according to some probability distribution with full support on $G$.

Experimentation, thus, is any deviation from copycat behaviour. It may occur due to error, inertia, political considerations outside the model etc. Since experimentation has full support, it also encompasses to (occasionally) choose best-response tax rates.

A state of these imitation dynamics is an element of $G^{n}$. The dynamics is an (ergodic) Markov chain in discrete time, indexed by the experimentation probability $\varepsilon$. The stochastically stable states are those tax vectors $\mathbf{t} \in G^{n}$ that are in the support of the (limit) invariant distribution of the Markov chain as $\varepsilon$ goes to zero (Kandori et al., 1993). They can be interpreted as the long-run outcomes of the rule to imitate best-performing tax strategies.

Kandori and Rob (1995) showed that the stochastically stable states comprise those monomorphic states $\mathbf{t}=(t, \ldots, t) \in G^{n}$ where the minimum number of experiments needed to reach $\mathbf{t}$ is as small as possible. It is therefore helpful to introduce the concept of a globally surviving strategy (alternatively labelled invading or $(n-1)$-stable strategy). According to Tanaka (2000), a strategy $t^{G} \in T$ is called a globally surviving strategy (GSS) if

$$
\pi\left(t^{G} ; t, \ldots, t\right) \geq \pi\left(t ; t^{G}, t, \ldots, t\right) \quad \text { for all } t \in T \text {. }
$$

Hence, a GSS is a tax rate that, if set by a single experimentator, can invade any profile where all other jurisdictions adopt an identical but different tax rate. ${ }^{15}$ The crucial feature of the tax competition game is that the globally survivng strategy and the ESS coincide. Formally,

Lemma $1 t^{G}=t^{E}$ (as implicitly defined in (13)) is the unique globally surviving strategy of the tax competition game.

\footnotetext{
${ }^{15}$ Consider a situation where all jurisdictions set the same tax rate $t$. If, when only one jurisdiction experiments with a different tax $t^{G}$ and then its social welfare is higher than anywhere else, and this holds for all strategies $t \neq t^{G}$, we call $t^{G}$ globally surviving.
} 
Proof. For $t^{\prime} \in T$, recall the following maximization problem:

$$
\max _{t \in T} \psi\left(t, t^{\prime}\right)
$$

where $\psi$ was defined in the previous subsection. Following Tanaka (2000), a strategy $t^{G}$ is globally surviving if and only if it solves the above problem for $t^{\prime}=t^{G}$, i.e., iff

$$
t^{G}=\arg \max _{t \in T} \psi\left(t, t^{G}\right) .
$$

However, then $t^{G}$ is also an ESS (see (9)).

By definition, in the imitation dynamics a globally stable state can be reached from any other monomorphic state after only one jurisdiction experiments with strategy $t^{G}$. On the other hand, to leave a state where an ESS $t^{E}$ is played to any other monomorphic state, it takes at least two experimentaing jurisdictions. This distinguishes an ESS from all other strategies. From Lemma $1, t^{G}$ and $t^{E}$ are identical in our set-up. Hence, the likelihood that $\mathbf{t}=\left(t^{E}, \ldots, t^{E}\right)$ is reached or maintained is higher than the likelihood that any other monomorphic state is reached or maintained. Consequently, ${ }^{16}$

Result 3 For the tax competition game, $\mathbf{t}=\left(t^{E}, \ldots, t^{E}\right)$ is the unique stochastically stable state of the imitation dynamics with experimentation.

This result indicates a close connection (precisely, an equivalence) between relative payoff maximization and the behavioural rule of adopting best practises. Moreover, in conjunction with Result 2, it states that adopting best practises in tax competition games will lead to a competitive situation with substantial underprovision of publicly provided consumption goods.

\section{Tax competition with publicly provided inputs}

So far, we have discussed tax competition when the governments use their tax revenues to finance a consumption good. Zodrow and Mieszkowski (1986) also discuss the case that government proceeds go to finance a public input. As was pointed out by Noiset (1995), Sinn (1997) or Dhillon et al. (2007), it is unclear in such a setup whether tax competition

\footnotetext{
${ }^{16}$ A similar result for Cournot oligopoly is obtained in Tanaka (2000). Alternatively, the proof could be built on the Radius-Coradius-Theorem as in Ania and Alòs-Ferrer (2005, Prop. 4). Also see Alòs-Ferrer and Schlag (2009, Section 3.2).
} 
triggers an under- or an overprovision of the public input. This makes fiscal competition with public inputs an interesting object of study also under the behavioural assumption that governments care for relative payoffs.

\subsection{The model}

We adopt the framework from Zodrow and Mieszkowski (1986, Section 3) or Noiset (1995): As before, an economically integrated area consists of $n>1$ identical jurisdictions, each inhabited by one (representative) immobile household who owns an (unmodelled) fixed factor and some initial stock of capital $\bar{k}>0$. Again, capital can be invested at home or abroad and is costlessly mobile.

Each country $i$ produces a single output $y_{i}$ (which also serves as the numéraire). At a unit marginal rate of transformation, $y_{i}$ can be used either for consumption, $c_{i}$, or as a publicly provided input, $z_{i}$, for production (say infrastructure). In addition to $z$, inputs in production are the amount $k_{i}$ of capital invested in jurisdiction $i$, and the fixed factor. The production technology is represented by a strictly quasi-convace production function $y_{i}=f\left(k_{i}, z_{i}\right)$ with positive, but decreasing marginal productivities $\left(f_{k}(k, z), f_{z}(k, z)>0\right.$ and $\left.f_{k k}(k, z), f_{z z}(k, z)<0\right)$. The Inada conditions are assumed to hold.

As before, government expenditures are financed through a source tax on capital. The government's budget constraint, thus, reads as

$$
t_{i} k_{i}=z_{i}
$$

The representative household in each country only cares about consumption, which is given by

$$
c_{i}=y_{i}-t_{i} k_{i}+\rho\left(\bar{k}-k_{i}\right)
$$

Again, $\rho$ denotes the (equilibrium) rate of return on capital, implicitly defined by the no-arbitrage condition

$$
f_{k}\left(k_{i}, z_{i}\right)-t_{i}=\rho \text { for all } i
$$

In this set of equations, we can replace the $z_{i}$ by the national budget constraints. Together with the requirement that all capital be invested somewhere in the economic area $\left(\sum k_{i}=\right.$ $n \cdot \bar{k})$, we then express the capital market equilibrium as a function merely of the tax rates $\mathbf{t}=\left(t_{1}, \ldots, t_{n}\right): k_{i}=k_{i}(\mathbf{t})$ and $\rho=\rho(\mathbf{t})$. As in Section 2 , we will focus on symmetric tax 
vectors $\left(t_{i}=t\right.$ and $k_{i}=\bar{k}$ for all $\left.i\right)$. We define shortcuts

$$
\begin{aligned}
A(t) & :=f_{k k}(\bar{k}, t \bar{k})+t \cdot f_{k z}(\bar{k}, t \bar{k}) \\
B(t) & :=\bar{k} \cdot f_{k z}(\bar{k}, t \bar{k})-1 .
\end{aligned}
$$

It can be shown that $A(t)<0$ in an equilibrium. ${ }^{17}$ For symmetric $\mathbf{t}=(t, \ldots, t)$, comparative statics under the condition that government budgets balance are given by: ${ }^{18}$

$$
\begin{aligned}
\frac{\partial k_{i}}{\partial t_{i}} & =-\frac{n-1}{n} \cdot \frac{B(t)}{A(t)} ; \\
\frac{\partial k_{j}}{\partial t_{i}} & =\frac{1}{n} \cdot \frac{B(t)}{A(t)} .
\end{aligned}
$$

Higher taxes in a jurisdiction will decrease the amount of capital invested there and, consequently, increase the amount of capital elsewhere if and only if $B(t)<0$.

As individuals only care for consumption, a benevolent government will pursue the maximization of $c_{i}$ as its policy objective. Expressed as functions of the tax vector, government payoffs $\pi_{i}=c_{i}$ emerge as

$$
\pi_{i}=\pi\left(t_{i} ; \mathbf{t}_{-i}\right)=f\left(k_{i}(\mathbf{t}), t_{i} k_{i}(\mathbf{t})\right)-t_{i} k_{i}(\mathbf{t})+\rho(\mathbf{t}) \cdot\left(\bar{k}-k_{i}(\mathbf{t})\right) .
$$

We now analyse symmetric Nash equilibria and ESS, analogously defined as in Section 2.2.

\subsection{Nash equilibria}

Payoff maximization requires that

$$
\begin{aligned}
0=\frac{\partial \pi_{i}}{\partial t_{i}} & =\left(f_{k}-t_{i}-\rho\right) \frac{\partial k_{i}}{\partial t_{i}}-k_{i}+\frac{\partial \rho}{\partial t_{i}}\left(\bar{k}-k_{i}\right)+f_{z}\left(k_{i}+t_{i} \frac{\partial k_{i}}{\partial t_{i}}\right) \\
& =-k_{i}+\frac{\partial \rho}{\partial t_{i}}\left(\bar{k}-k_{i}\right)+f_{z}\left(k_{i}+t_{i} \frac{\partial k_{i}}{\partial t_{i}}\right) .
\end{aligned}
$$

\footnotetext{
${ }^{17}$ See Noiset (1995, footnote 5$) . A(t)<0$ is equivalent to the budget deficit, $z-t k$, being (locally) increasing in $z$. In a symmetric situation $A(t)>0$ would imply that a marginal increase in $z$ finances itself and leads to a (small) budget surplus. This cannot hold in an optimum.

${ }^{18}$ For arbitrary (non-symmetric) tax vectors, define shortcuts $A_{i}:=f_{k k}\left(k_{i}, t_{i} k_{i}\right)+t_{i} \cdot f_{k z}\left(k_{i}, t_{i} k_{i}\right)$ and $B_{i}:=k_{i} \cdot f_{k z}\left(k_{i}, t_{i} k_{i}\right)-1$ for $i=1, \ldots, n$. Then comparative statics read as follows:

$$
\frac{\partial k_{i}(\mathbf{t})}{\partial t_{i}}=-\frac{B_{i} \sum_{h \neq i} \frac{1}{A_{h}}}{A_{i} \sum_{h=1}^{n} \frac{1}{A_{h}}} \quad \text { and } \quad \frac{\partial k_{i}(\mathbf{t})}{\partial t_{j}}=\frac{B_{j}}{A_{i} A_{j} \sum_{h=1}^{n} \frac{1}{A_{h}}}
$$
}

(where $i \neq j$ ). The symmetric case follows easily. 
In a symmetric Nash equilibrium $\left(t_{i}=t^{N}\right.$ for all $\left.i\right)$, this condition holds at $k_{i}=\bar{k}$. Hence, using (15) and (16), a symmetric Nash equilibrium is characterized by:

$$
\Gamma\left(t^{N}, n\right):=-1+f_{z}\left(\bar{k}, t^{N} \bar{k}\right) \cdot\left(1-\frac{t^{N}}{\bar{k}} \cdot \frac{n-1}{n} \cdot \frac{B\left(t^{N}\right)}{A\left(t^{N}\right)}\right)=0 .
$$

Condition (18) implies that

$$
\begin{aligned}
f_{z}\left(\bar{k}, t^{N} \bar{k}\right) \geq 1 & \Longleftrightarrow B\left(t^{N}\right) \leq 0 \\
& \Longleftrightarrow \bar{k} \cdot f_{k z}(\bar{k}, t \bar{k}) \leq 1 .
\end{aligned}
$$

Result 4 (i) (Noiset, 1995) The Nash equilibrium of the tax competition game with publicly provided inputs entails underprovision [overprovision] of the governmentprovided $\operatorname{good}$ if $k \cdot f_{k z}(k, z)<1$ [if $k \cdot f_{k z}(k, z)>1$ ].

(ii) Both underprovision and overprovision will be more pronounced the larger the number of countries, $n$.

\section{Proof:}

(i) Efficiency requires that $f_{z}(\bar{k}, z)=1$ (recall that the MRT between private consumption and the publicly provided good equals one). The first item of the proposition thus follows from (19) and the strict concavity of $f(\bar{k}, z)$ in $z$.

(ii) Observe that (18) implicitly defines the Nash equilibrium tax rate (which is a perfect indicator for over- or underprovision since $z=t \bar{k}$ ) as a function of $n$. Treating $n$ as a continuous variable for sake of simplicity, we get that $\partial t^{N} / \partial n=-\frac{\partial \Gamma / \partial n}{\partial \Gamma / \partial t}$. Here, the denominator is negative from the second-order condition (recall that $t^{N}$ is a maximizer). Hence, $t^{N}$ is increasing [decreasing] in $n$ whenever $\Gamma$ increases [decreases] in $n$. As the term $(n-1) / n$ grows in $n$ and as $A\left(t^{N}\right)$ is negative, $\Gamma$ (and thus $t^{N}$ ) increases [decreases] in $n$ if and only if $B>0$ [if $B<0$ ]. In conjunction with item (i), the claim follows.

Tax competition, thus, typically results in an inefficient allocation. However, depending on the strength with which the publicly provided input affects the marginal productivity of capital, also a race-over-the-top with respect to tax rates is possible. Specifically, the condition for underprovision $\left(k \cdot f_{k z}(k, z)<1\right)$ requires that an extra unit of the publicly provided input raises the marginal productivity of capital by less than its marginal cost for investors in terms of additional taxation. Generally, the inefficiency (in whatever direction) is more pronounced the more countries participate in the tax competition game. 


\section{$3.3 \quad$ ESS}

To derive ESS, we proceed as in Section 2.5. Given two tax rates $t, t^{\prime} \in T$, we define variables $t^{1}\left[t, t^{\prime}\right], t^{2}\left[t, t^{\prime}\right]$, and $\psi\left(t, t^{\prime}\right)$ as before, replacing $\pi$ by (17). Hence, we are now searching for that tax rate $t$ that maximizes

$$
\begin{aligned}
\psi\left(t, t^{\prime}\right)= & f\left(k_{1}\left(\mathbf{t}^{1}\right), t \cdot k_{1}\left(\mathbf{t}^{1}\right)\right)-t k_{1}\left(\mathbf{t}^{1}\right) \\
& -f\left(k_{2}\left(\mathbf{t}^{2}\right), t^{\prime} \cdot k_{2}\left(\mathbf{t}^{2}\right)\right)-t^{\prime} k_{1}\left(\mathbf{t}^{1}\right)+\rho\left(\mathbf{t}^{1}\right) \cdot\left(\bar{k}_{2}\left(\mathbf{t}^{2}\right)-k_{1}\left(\mathbf{t}^{1}\right)\right)
\end{aligned}
$$

at $t=t^{\prime}$ (observe that $\rho\left(\mathbf{t}^{1}\right)=\rho\left(\mathbf{t}^{2}\right)$ ). Partial differentiation, applying the notational convention agreed upon in Section 2.4, yields

$$
\frac{\partial \psi\left(t, t^{\prime}\right)}{\partial t}=-k_{1}+\frac{\partial \rho\left(\mathbf{t}^{1}\right)}{\partial t} \cdot\left(k_{2}-k_{1}\right)+f_{z}^{1} \cdot\left(k_{1}+t \cdot \frac{\partial k_{1}}{\partial t}\right)-f_{z}^{2} \cdot t^{\prime} \cdot \frac{\partial k_{2}}{\partial t} .
$$

At a symmetric profile $\left(t=t^{\prime}\right)$, we have $\mathbf{t}^{1}=\mathbf{t}^{2}, k_{1}=k_{2}=\bar{k}$, and $z_{1}=z_{2}=t^{\prime} \bar{k}$. Since an ESS $t^{E}$ maximizes $\psi\left(t, t^{E}\right)$, it satisfies

$$
-\bar{k}+f_{z} \cdot\left(\bar{k}+t \cdot\left(\frac{\partial k_{1}}{\partial t_{1}}-\frac{\partial k_{2}}{\partial t_{1}}\right)\right)=0
$$

or, using (15) and (16),

$$
-1+f_{z}\left(\bar{k}, t^{E} \bar{k}\right) \cdot\left(1-\frac{t^{E}}{\bar{k}} \cdot \frac{B\left(t^{E}\right)}{A\left(t^{E}\right)}\right)=0 .
$$

The LHS corresponds to $\Gamma\left(t^{E}, \infty\right)$. In analogy with Result 2 we, thus, obtain

Result 5 An ESS of a tax competition game with publicly provided inputs is, for any number of countries, identical to the competitive Nash equilibrium of that game.

As in Section 2, the ESS of the tax competition game is independent of the number of participating jurisdictions (unlike the Nash equilibrium). Compared to tax competition with payoff maximization, relative payoff concerns exacerbate inefficiencies. In contrast to the framework in Section 2, the inefficiency here may imply an overprovison of government goods (too high tax rates). Relative payoff concerns, thus, not only accelerate races-tothe-bottom but also speed up races-over-the-top.

The intuition for Result 5 is similar to that for Result 2. Depending on whether a higher tax rate in one jurisdiction reduces or increases the amount of capital invested in other jurisdictions (i.e., depending on whether $B>0$ or $B<0$ ), relative performance concerns in tax competition trigger an additional incentive (out of spite) for each jurisdiction to 
increase or to lower the own tax rate. Such a move would widen the differential in capital stocks (i.e., $k_{i}-k_{j}$ ). The magnitude of this effect is independent of the number of jurisdictions since, as above, repercussions through the net-rate-of-return cancel out. Irrelevance of the number of jurisdictions, however, is de facto identical to the competitive scenario in tax competition with absolute payoff maximization.

Also for tax competition with publicly provided inputs we can analyse imitation dynamics with experimentation as in Section 2.5. As the result is identical, we refrain from elaborating on this here: the ESS (or, from Result 5, the competitive Nash equilibrium) emerges as the unique stochastically stable state.

\section{Conclusions}

Governments that care for their standing vis-à-vis fellow governments elsewhere or governments that copy (successful) policies from elsewhere engage in more aggressive fiscal competition than those focussed on payoff maximization. Their incentives to underbid each other in tax rates or to overbid one another with public infrastructure are sharpened. As a consequence, aggregate and individual performance in tax competition is worse than with governments that set tax policies as best replies in a fiscal game.

We arrived at these findings in the standard tax competition framework due to Zodrow and Mieszkowski (1986). Being a workhorse in the theory of fiscal federalism, this model has undergone many modifications and extensions (see Wilson, 1999, for a survey). In future research, these variants of tax competition could be analysed from a behavioural perspective on governments, allowing for relative performance concerns and copycat strategies. Given that in games with a small number of players, the relationship between ESS and Nash equilibria is still not fully understood (see Guse et al., 2008, or Alòs-Ferrer and Ania, 2005), many interesting and potentially surprising results on tax competition can be expected from such studies. 


\section{References}

Allers, Maarten A., and J. Paul Elhorst (2005): Tax Mimicking and Yardstick Competition Among Local Governments in the Netherlands. International Tax and Public Finance $12,493-513$.

Alòs-Ferrer, Carlos, and Ana B. Ania (2005): The Evolutionary Stability of Perfectly Competitive Behavior. Economic Theory 26, 497-516.

Alòs-Ferrer, Carlos, and Karl Schlag (2009): Imitation and Learning. In: Paul Anand, Prasanta Pattanaik, and Clemens Puppe, eds., Handbook of Rational and Social Choice, Oxford University Press, 271-296.

Altshuler, Rosanne, and Timothy Goodspeed (2006): Follow the Leader? Evidence on European and U.S. Tax Competition. Mimeo.

Besley, Timothy, and Ann Case (1995): Incumbent Behavior: Vote-Seeking, Tax-Setting, and Yardstick Competition. American Economic Review 85, 25-45.

Bordignon, Massimo, Floriana Cerniglia, and Federico Revelli (2003): In Search of Yardstick Competition: A Spatial Analysis of Italian Municipality Property Tax Setting. Journal of Urban Economics 54, 199-217.

Borrás, Susana, and Kerstin Jacobsson (2004): The Open Method of Co-ordination and New Governance Patterns in the EU. Journal of European Public Policy 11, 185-202.

Büttner, Thiess (2001): Local Business Taxation and Competition for Capital: The Choice of Tax Rate. Regional Science and Urban Economics 31, 215-245.

Case, Anne (1993): Interstate Tax Competition after TRA86. Journal of Policy Analysis and Management 12, 136-148.

Dhillon, Amrita, Myrna Wooders, and Ben Zissimos (2007): Tax Competition Reconsidered. Journal of Public Economic Theory 9, 391-423. 
Feld, Lars, and Emmanuelle Reulier (2009): Strategic Tax Competition in Switzerland. Evidence from a Panel of the Swiss Cantons. German Economic Review 10, 91-114.

Fredriksson, Per G., John List, and Daniel A. Millimet (2004): Chasing the Smokestack: Strategic Policymaking with Multiple Instruments. Regional Science and Urban Economics $34,387-410$.

Geys, Benny (2006): Looking Across Borders: A Test of Spatial Policy Interdependence Using Local Government Efficiency Ratings. Journal of Urban Economics 60, 443-462.

Guse, Thomas, Burkhard Hehenkamp, and Alex Possajennikov (2008): On the Equivalence of Nash and Evolutionary Equilibrium in Finite Populations, CeDEx Discussion Paper No. 2008-06.

Hamilton, William D. (1970): Selfish and Spiteful Behavior in an Evolutionary Model. Nature 228, 12181220.

Heyndels, Bruno, and Jef Vuchelen (1998): Tax Mimicking among Belgian Municipalities. National Tax Journal 51, 89-100.

Hoyt, William H. (1991): Property Taxation, Nash Equilibrium, and Market Power. Journal of Urban Economics 30, 123-131.

Inman, Robert, and Daniel L. Rubinfeld (1997): Rethinking Federalism, Journal of Economic Perspectives 11, 43-64.

Kandori, Michihiro, and Rafael Rob (1995): Evolution of Equilibria in the Long Run: A General Theory and Applications. Journal of Economic Theory 65, 383-414.

Kandori, Michihiro, George J. Mailath and Rafael Rob (1993): Learning, Mutation, and Long Run Equilibria in Games. Econometrica 61, 29-56.

Kelejian, Harry H., and Dennis P. Robinson (1993): A Suggested Method of Estimation for Spatial Interdependent Models with Autocorrelated Errors, and an Application to a County Expenditure Model. Papers in Regional Science 72, 297-312. 
Kollman, Ken, John H. Miller, and Scott E. Page (2000): Decentralization and the Search for Policy Solutions. Journal of Law, Economics, and Organization 16, 102-128.

Kotsogiannis, Christos , and Robert Schwager (2007): On the Incentives to Experiment in Federations. Journal of Urban Economics 60, 484-497.

Ladd, Helen F. (1992): Mimicking of Local Tax Burdens Among Neighboring Counties. Public Finance Quarterly 20, 450-467.

Noiset, Luc (1995): Pigou, Tiebout, Property Taxation, and the Underprovision of Local Public Goods: Comment. Journal of Urban Economics 38, 312-316.

Salmon, Pierre (1987): Decentralization as an Incentive Scheme. Oxford Review of Economic Policy 3, 24-43.

Schaffer, Mark E. (1988): Evolutionarily Stable Strategies for a Finite Population and a Variable Contest Size. Journal of Theoretical Biology 132, 469-478.

Schenk-Hoppé, Klaus R. (2000): The Evolution of Walrasian Behavior in Oligopolies. Journal of Mathematical Economics 33, 35-55.

Sinn, Hans-Werner (1997): The Selection Principle and Market Failure in Systems of Competition. Journal of Public Economics 66, 247-274.

Solé-Ollé, Albert (2003): Electoral Accountability and Tax Mimicking: The Effects of Electoral Margins, Coalition Government and Ideology. European Journal of Political Economy 19, 685-713.

Tanaka, Yasuhito (2000): Stochastically Stable States in an Oligopoly with Differentiated Goods: Equivalence of Price and Quantity Strategies. Journal of Mathematical Economics 34, 235-253.

Vega-Redondo, Fernando (1997): The Evolution of Walrasian Behavior. Econometrica $65,375-384$. 
Wilson, John D. (1999): Theories of Tax Competition. National Tax Journal 52, 269-304.

Wilson, John D. (1986): A Theory of Interregional Tax Competition. Journal of Urban Economics 19, 296-315.

Zeitlin, Jonathan (2005): Social Europa and Experimentalist Governance: Towards a New Constitutional Compromise? European Governance Papers (EUROGOV) No. C-05-04.

Zodrow, G.R., and Peter Mieszkowski (1986): Pigou, Tiebout, Property Taxation, and the Underprovision of Local Public Goods. Journal of Urban Economics 19, 356-370. 


\section{CESifo Working Paper Series}

for full list see www.cesifo-group.org/wp

(address: Poschingerstr. 5, 81679 Munich, Germany, office@cesifo.de)

2661 Oliver Falck, Stephan Heblich and Elke Luedemann, Identity and Entrepreneurship, May 2009

2662 Christian Lessmann and Gunther Markwardt, One Size Fits All? Decentralization, Corruption, and the Monitoring of Bureaucrats, May 2009

2663 Felix Bierbrauer, On the Legitimacy of Coercion for the Financing of Public Goods, May 2009

2664 Alessandro Cigno, Agency in Family Policy: A Survey, May 2009

2665 Claudia M. Buch and Christian Pierdzioch, Low Skill but High Volatility?, May 2009

2666 Hendrik Jürges, Kerstin Schneider, Martin Senkbeil and Claus H. Carstensen, Assessment Drives Learning: The Effect of Central Exit Exams on Curricular Knowledge and Mathematical Literacy, June 2009

2667 Eric A. Hanushek and Ludger Woessmann, Schooling, Cognitive Skills, and the Latin American Growth Puzzle, June 2009

2668 Ourania Karakosta, Christos Kotsogiannis and Miguel-Angel Lopez-Garcia, Does Indirect Tax Harmonization Deliver Pareto Improvements in the Presence of Global Public Goods?, June 2009

2669 Aleksandra Riedl and Silvia Rocha-Akis, Testing the Tax Competition Theory: How Elastic are National Tax Bases in OECD Countries?, June 2009

2670 Dominique Demougin and Carsten Helm, Incentive Contracts and Efficient Unemployment Benefits, June 2009

2671 Guglielmo Maria Caporale and Luis A. Gil-Alana, Long Memory in US Real Output per Capita, June 2009

2672 Jim Malley and Ulrich Woitek, Productivity Shocks and Aggregate Cycles in an Estimated Endogenous Growth Model, June 2009

2673 Vivek Ghosal, Business Strategy and Firm Reorganization under Changing Market Conditions, June 2009

2674 Francesco Menoncin and Paolo M. Panteghini, Retrospective Capital Gains Taxation in the Real World, June 2009

2675 Thomas Hemmelgarn and Gaëtan Nicodème, Tax Co-ordination in Europe: Assessing the First Years of the EU-Savings Taxation Directive, June 2009 
2676 Oliver Himmler, The Effects of School Competition on Academic Achievement and Grading Standards, June 2009

2677 Rolf Golombek and Michael Hoel, International Cooperation on Climate-Friendly Technologies, June 2009

2678 Martin Cave and Matthew Corkery, Regulation and Barriers to Trade in Telecommunications Services in the European Union, June 2009

2679 Costas Arkolakis, A Unified Theory of Firm Selection and Growth, June 2009

2680 Michelle R. Garfinkel, Stergios Skaperdas and Constantinos Syropoulos, International Trade and Transnational Insecurity: How Comparative Advantage and Power are Jointly Determined, June 2009

2681 Marcelo Resende, Capital Structure and Regulation in U.S. Local Telephony: An Exploratory Econometric Study; June 2009

2682 Marc Gronwald and Janina Ketterer, Evaluating Emission Trading as a Policy Tool Evidence from Conditional Jump Models, June 2009

2683 Stephan O. Hornig, Horst Rottmann and Rüdiger Wapler, Information Asymmetry, Education Signals and the Case of Ethnic and Native Germans, June 2009

2684 Benoit Dostie and Rajshri Jayaraman, The Effect of Adversity on Process Innovations and Managerial Incentives, June 2009

2685 Peter Egger, Christian Keuschnigg and Hannes Winner, Incorporation and Taxation: Theory and Firm-level Evidence, June 2009

2686 Chrysovalantou Milliou and Emmanuel Petrakis, Timing of Technology Adoption and Product Market Competition, June 2009

2687 Hans Degryse, Frank de Jong and Jérémie Lefebvre, An Empirical Analysis of Legal Insider Trading in the Netherlands, June 2009

2688 Subhasish M. Chowdhury, Dan Kovenock and Roman M. Sheremeta, An Experimental Investigation of Colonel Blotto Games, June 2009

2689 Alexander Chudik, M. Hashem Pesaran and Elisa Tosetti, Weak and Strong Cross Section Dependence and Estimation of Large Panels, June 2009

2690 Mohamed El Hedi Arouri and Christophe Rault, On the Influence of Oil Prices on Stock Markets: Evidence from Panel Analysis in GCC Countries, June 2009

2691 Lars P. Feld and Christoph A. Schaltegger, Political Stability and Fiscal Policy - Time Series Evidence for the Swiss Federal Level since 1849, June 2009

2692 Michael Funke and Marc Gronwald, A Convex Hull Approach to Counterfactual Analysis of Trade Openness and Growth, June 2009 
2693 Patricia Funk and Christina Gathmann, Does Direct Democracy Reduce the Size of Government? New Evidence from Historical Data, 1890-2000, June 2009

2694 Kirsten Wandschneider and Nikolaus Wolf, Shooting on a Moving Target: Explaining European Bank Rates during the Interwar Period, June 2009

2695 J. Atsu Amegashie, Third-Party Intervention in Conflicts and the Indirect Samaritan's Dilemma, June 2009

2696 Enrico Spolaore and Romain Wacziarg, War and Relatedness, June 2009

2697 Steven Brakman, Charles van Marrewijk and Arjen van Witteloostuijn, Market Liberalization in the European Natural Gas Market - the Importance of Capacity Constraints and Efficiency Differences, July 2009

2698 Huifang Tian, John Whalley and Yuezhou Cai, Trade Sanctions, Financial Transfers and BRIC's Participation in Global Climate Change Negotiations, July 2009

2699 Axel Dreher and Justina A. V. Fischer, Government Decentralization as a Disincentive for Transnational Terror? An Empirical Analysis, July 2009

2700 Balázs Égert, Tomasz Koźluk and Douglas Sutherland, Infrastructure and Growth: Empirical Evidence, July 2009

2701 Felix Bierbrauer, Optimal Income Taxation and Public Goods Provision in a Large Economy with Aggregate Uncertainty, July 2009

2702 Marc Gronwald, Investigating the U.S. Oil-Macroeconomy Nexus using Rolling Impulse Responses, July 2009

2703 Ali Bayar and Bram Smeets, Government Deficits in the European Union: An Analysis of Entry and Exit Dynamics, July 2009

2704 Stergios Skaperdas, The Costs of Organized Violence: A Review of the Evidence, July 2009

2705 António Afonso and Christophe Rault, Spend-and-tax: A Panel Data Investigation for the EU, July 2009

2706 Bruno S. Frey, Punishment - and beyond, July 2009

2707 Michael Melvin and Mark P. Taylor, The Crisis in the Foreign Exchange Market, July 2009

2708 Firouz Gahvari, Friedman Rule in a Model with Endogenous Growth and Cash-inadvance Constraint, July 2009

2709 Jon H. Fiva and Gisle James Natvik, Do Re-election Probabilities Influence Public Investment?, July 2009 
2710 Jarko Fidrmuc and Iikka Korhonen, The Impact of the Global Financial Crisis on Business Cycles in Asian Emerging Economies, July 2009

2711 J. Atsu Amegashie, Incomplete Property Rights and Overinvestment, July 2009

2712 Frank R. Lichtenberg, Response to Baker and Fugh-Berman's Critique of my Paper, "Why has Longevity Increased more in some States than in others?", July 2009

2713 Hans Jarle Kind, Tore Nilssen and Lars Sørgard, Business Models for Media Firms: Does Competition Matter for how they Raise Revenue?, July 2009

2714 Beatrix Brügger, Rafael Lalive and Josef Zweimüller, Does Culture Affect Unemployment? Evidence from the Röstigraben, July 2009

2715 Oliver Falck, Michael Fritsch and Stephan Heblich, Bohemians, Human Capital, and Regional Economic Growth, July 2009

2716 Wladimir Raymond, Pierre Mohnen, Franz Palm and Sybrand Schim van der Loeff, Innovative Sales, R\&D and Total Innovation Expenditures: Panel Evidence on their Dynamics, July 2009

2717 Ben J. Heijdra and Jochen O. Mierau, Annuity Market Imperfection, Retirement and Economic Growth, July 2009

2718 Kai Carstensen, Oliver Hülsewig and Timo Wollmershäuser, Price Dispersion in the Euro Area: The Case of a Symmetric Oil Price Shock, July 2009

2719 Katri Kosonen and Gaëtan Nicodème, The Role of Fiscal Instruments in Environmental Policy, July 2009

2720 Guglielmo Maria Caporale, Luca Onorante and Paolo Paesani, Inflation and Inflation Uncertainty in the Euro Area, July 2009

2721 Thushyanthan Baskaran and Lars P. Feld, Fiscal Decentralization and Economic Growth in OECD Countries: Is there a Relationship?, July 2009

2722 Nadia Fiorino and Roberto Ricciuti, Interest Groups and Government Spending in Italy, 1876-1913, July 2009

2723 Andreas Wagener, Tax Competition, Relative Performance and Policy Imitation, July 2009 